\title{
THREE PHASE VIENNA RECTIFIER FOR WIND POWER GENERATION SYSTEM
}

\author{
Bhumika $\mathbf{S}^{1}$, Shri Harsha $\mathbf{J}^{2}$ \\ ${ }^{1}$ Student, EEE Department, Sri Siddhartha Institute of Technology, Tumkur, Karnataka, India \\ ${ }^{2}$ Asst. Professor, EEE Department, Sri Siddhartha Institute of Technology, Karnataka, India
}

\begin{abstract}
In recent years, wind energy technology has become one of the top areas of interest for energy harvesting in the power electronics world. Wind energy conversion system is a system that converts kinetic energy of the wind into electricity. The primary focus of this project is to design and implement the power electronics converter (AC_DC) of a wind energy conversion system. The aim is to develop an interface between a three-phase AC generator operating at variable speed (e.g. wind generators) and a constant voltage $D C$-bus. The interface is required to ensure high energy efficiency by reducing reactive power consumption, as well as maintaining a constant DC-bus voltage. This paper deals with the design and evaluation of power electronics topology commonly called the "Vienna rectifier" that can be used for improved variable-speed wind energy conversion. The main advantage for the VIENNA converter with PFC allows more power extraction from the turbine, increasing both electrical and mechanical efficiency.
\end{abstract}

Keywords: Vienna Rectifier, Three Phase PFC, Active Rectification

\section{INTRODUCTION}

AC-DC converters find application in everyday-life as a frontend to DC-DC and DC-AC converters. In low power with low cost applications, the AC to DC conversion is very often merely a diode bridge rectifier with capacitor voltage filter. However, bridge rectification inherently draws non-sinusoidal current from the mains, which make it inadequate for high power applications due to the strict regulations on conducted EM (electromagnetic) energy, as well as the high current stress on components. For high power applications, the sinusoidal current must be actively shaped by using either a boost type front-end converter or by complex EM filtering at the input. Research and development of the latter has ceased mainly due to the cost and size associated with EM filters.

As wind generators as an energy source became more popular. Based on turbine rotation the synchronous generator generates the variable three phase $\mathrm{AC}$ input voltage. It has to be converted to high voltage DC (HVDC) to connect to the grid. The need arises to efficiently convert the energy provided to a usable source and also conserve energy by reducing reactive power consumption. The interface developed in this paper will serve as a possible solution for fulfilling this need. The interface is three phase three switch, three levels VIENNA rectifier.

The rectifier control scheme proposed in this paper ensured a unity power factor at the source input. This implies that the input current is both sinusoidal and in-phase with the input voltage, assuming that the input voltage is also sinusoidal. Proposed Vienna Rectifier with power factor correction scheme incorporated with wind power conversion system reduces the switching stress and losses as three switches are used rather than six switch active rectifier. As the input is dynamic three phase AC a PI controller is designed and tuned to get the constant output DC voltage of desired level with unity power factor.

\section{METHODOLOGY}

The wind turbine along with the Vienna rectifier deals with the reduction of line harmonics and switching losses are reduced. In this paper novel scalar control technique is used for controlling the switching and hence Dc output will stabilize. Vienna rectifier is three phases, three switches, three level rectifier where power factor correction is done using a better scalar controlling scheme. As the pulse number increases, the harmonics present in the input decreases and the total harmonic distortion reduces.

The output of the wind turbine varies according to the wind but while connecting to load we have to maintain constant voltage so to step up \& step down the voltages in rectifier section a three switch Vienna rectifier is implemented. The wind turbine converts the kinetic energy present in the wind into mechanical energy. The output of the wind turbine is connected to Synchronous generator. The generator converts the mechanical energy into electrical energy. The output of the generator is connected to Vienna rectifier; it converts the unstable AC voltage into stable DC voltage and input line current is sinusoidal hence unity power factor is obtained. The Vienna rectifier is used to make power factor correction and 
only three IGBT switches are used so switching loss is reduced. The output of the Vienna rectifier is given to battery

\section{BASICS OF VIENNA RECTIFIER}

The Vienna rectifier consists of three switches IGBT; It converts the unstable $\mathrm{AC}$ voltage into controlled $\mathrm{DC}$ voltage. It can also provide sinusoidal input currents and controlled DC-voltage. The AC voltage from the three phase generator is given to the Vienna rectifier. The current flows through the three IGBTs and the capacitors in the capacitor bank begin to charge and when the capacitors are fully charged it.

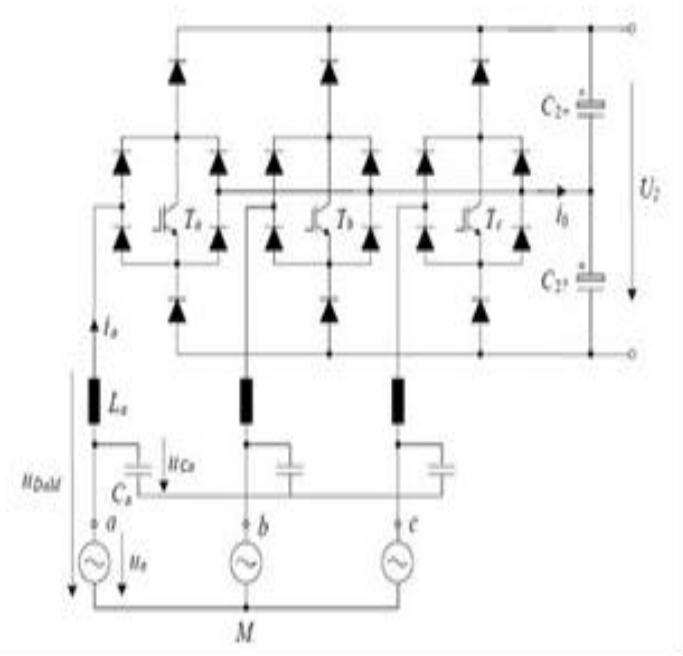

Fig -1: Vienna Rectifier

It compensates the reactive power and hence the power factor is improved. The topology of the three-phase/threeswitch/three-level PWM ("Vienna") rectifier is depicted in circuit diagram Figure.1. Herein, we consider the electromechanical system until the dc bus, which is assumed to maintain a constant dc voltage. The switches are placed and the switching is made in such a way that the numbers of solid state switches are reduced.

The PWM block is made to generate the gating signals for IGBT. In Vienna Rectifier the output capacitor is split in two parts as two equal value capacitors, $\mathrm{C} 1$ and $\mathrm{C} 2$, connected in series. Across the output capacitors the $-\mathrm{Vdc}$ and $+\mathrm{Vdc}$ are developed as 3-Phase peak detected outputs. A switch for each phase is connected, such that when "ON", it connects the line phase to the center node of $\mathrm{C} 1$ and $\mathrm{C} 2$ through a series inductance. For a short switching period, the capacitors charge linearly. This offsets $-\mathrm{Vdc}$ and $+\mathrm{Vdc}$. Proper switching control strategy for switching will boost the Dc voltage to desired level and power factor correction is done so that input current is sinusoidal and follows voltage phase leading to unity power factor.

\subsection{Switching Strategy of Vienna Rectifier}

The Vienna rectifier has three switches, and by choosing their (ON\OFF) state considering the polarity of the phase current in each phase, the voltage for each phase will be determined. So, the phase voltage is depending on the direction of phase current and switch position State of the switch (ON/OFF) and the polarity of the line current in each phase determine the rectifier pole voltages (VAM, VBM, VCM) at any instant of operation. In order to discuss operation principles of the rectifier, here Phase A is explained. Phase B and C have the same behavior. If the line current is positive, and the switch Ta is off, the current flows through diode D11, and the voltage between the converter pole $\mathrm{A}$ and the $\mathrm{DC}$ bus midpoint $\mathrm{M}$ (i.e. $\mathrm{VAM}$ ) is $\mathrm{DC} / 2$. The conduction path for this case is illustrated in Figure 2(a). If the polarity of the line current is positive, and the switch Ta is on, the voltage VAM is 0 , in which the conduction path is illustrated in Figure 2(b) Similarly, the voltage VAM can be determined in other states as illustrated in Figure 2(c) and (d).This operating principle also can apply to Phase $\mathrm{B}$ and $\mathrm{C}$ to determine VBM and VCM.
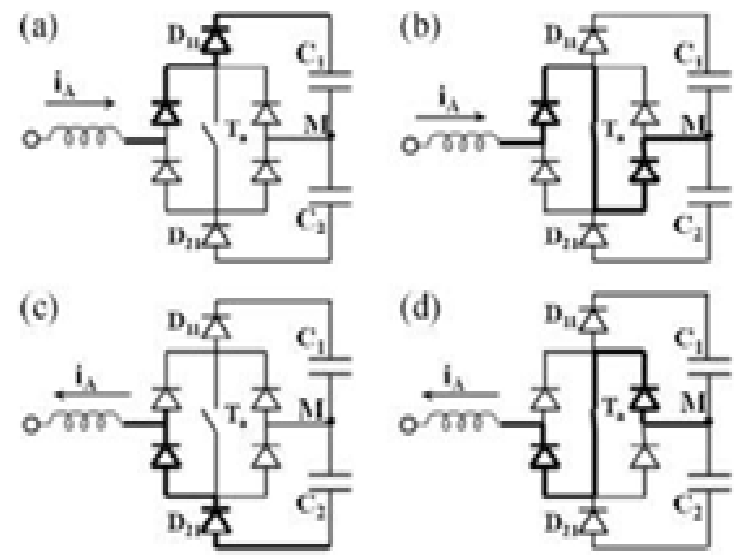

Fig.2: Conduction paths for phase-leg A when(a) The line current is positive, and the controlled switch is off (b) The line current is positive, and the controlled switch is on (c) The line current is negative, and the controlled switch is off and (d) The line current is negative, and the controlled switch is on.

Here switching is controlled using pi controller such that input current will be made to follow the sinusoidal voltage waveform thus reducing the harmonics and correcting the power factor hence input current control. The output DC voltage is also boosted output and hence using PI voltage controller desired DC voltage is obtained

\subsection{Advantages of Vienna Rectifier}

- Gives continuous sinusoidal input current

- No need for a neutral wire. 
- Low number of IGBTs used and hence circuit complexity reduced.

- Reduction in switching loss of the power semiconductors by almost $40 \%$.

- Wide voltage range as the Boosting ability is present.

- Improved power factor and lower THD hence higher efficiency.

\section{CONTROL SCHEME FOR SWITCHING}

The Control Scheme for three phase Vienna rectifier is as depicted below. Here Active power factor correction scheme is used. The converter is considered to operating in the Continuous conduction mode as supply from power generator is consider to be continuous conduction mode Since the current across inductor is continuous stress is reduced. The Fig. 3 shows the control scheme for switching the three IGBT switches of Vienna rectifier.

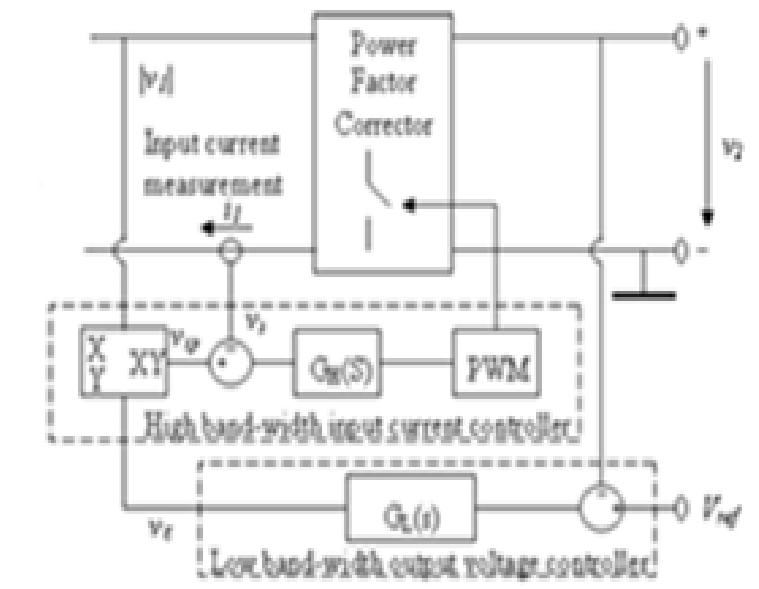

Fig.3: Control scheme for switching IGBTs

The low-bandwidth outer loop with characteristic GL(s) is used to keep the output voltage of the PFC stage constant and to provide the error signal .The high-bandwidth inner loop with characteristic GH(s) is used to control the input current. A multiplier Vxy is used to provide a reference $\mathrm{Vg}$, which is proportional to the error signal $\mathrm{V} \varepsilon$ and which has a modulating signal with the desired shape for the input current

In this case the modulating signal is $\mathrm{Vxy}=\mathrm{V} \varepsilon$ and it is essentially constant over the line cycle, because $\mathrm{V} \varepsilon$ is the control signal from the low-bandwidth output voltage controller. Therefore, the input current is sinusoidal and proportional to input voltage hence power factor will be made to unity and reduced harmonics due to compensating strategy. Of all the control strategies active control is most preferred. The inductor current is sensed and filtered by a current error amplifier whose output drives a PWM modulator. In this way the inner current loop tends to minimize the error between the average input current and its reference and Unity power factor is obtained and reducing the total harmonic distortion(THD).

\section{SIMULATION RESULTS}

The Feasibility of proposed Vienna rectifier with PI Controller is proved with MATLAB Simulink V2012b. Fig.4 shows the Simulink model and results are obtained for input voltage $100 \mathrm{VAC}$ and frequency of $60 \mathrm{HZ}$. The waveforms are shown as shown in Fig 5 (a) and 7.2 (b). The same waveform is obtained for varying input condition as controller is tuned to get desired output.

\subsection{Simulation Parameters}

Simulation parameters are as listed in the table below. The parameters are designed to get the output of desired level. Simulation time is $10 \mu \mathrm{S}$ and switching frequency or frequency of repetitive sequence is $10 \mathrm{KHz}$ for various input voltages the output is evaluated as in wind power generation we get varying input voltage based on turbine rotation.

Table.1 List of Simulation Parameters and its Values

\begin{tabular}{|l|l|l|}
\hline Parameter & Symbol & Value \\
\hline Simulation time & Ts & $10 \mu \mathrm{S}$ \\
\hline Inductance & $\mathrm{L}$ & $4 \eta \mathrm{H}$ \\
\hline Capacitance & $\mathrm{C}$ & $3 \mathrm{mF}$ \\
\hline Load Resistance & $\mathrm{R}$ & $10 \mathrm{~K} \Omega$ \\
\hline $\begin{array}{l}\text { Nominal Three phase Input } \\
\text { Voltage(Varying) }\end{array}$ & Vin & $100 \quad$ V- \\
\hline $\begin{array}{l}\text { Nominal Three Phase Input } \\
\text { Current }\end{array}$ & Iin & $10 \mathrm{~A}-30 \mathrm{~A}$ \\
\hline Input Frequency & $\mathrm{F}$ & $60 \mathrm{~Hz}$ \\
\hline Switching Frequency & Fs & $10 \mathrm{KHz}$ \\
\hline Proportionality Gain & $\mathrm{Kp}$ & 0.018 \\
\hline
\end{tabular}

\subsection{Simulation Circuit and Waveforms}

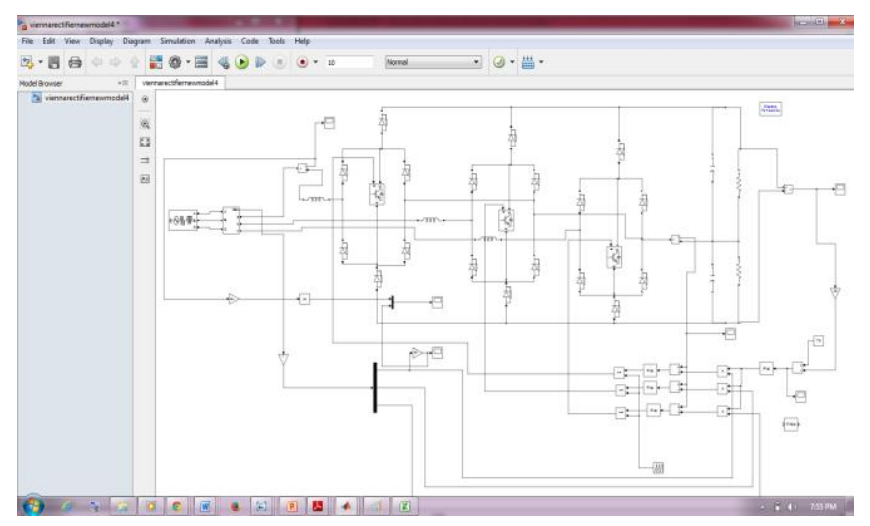

Fig.4: Power circuit of Vienna Rectifier 


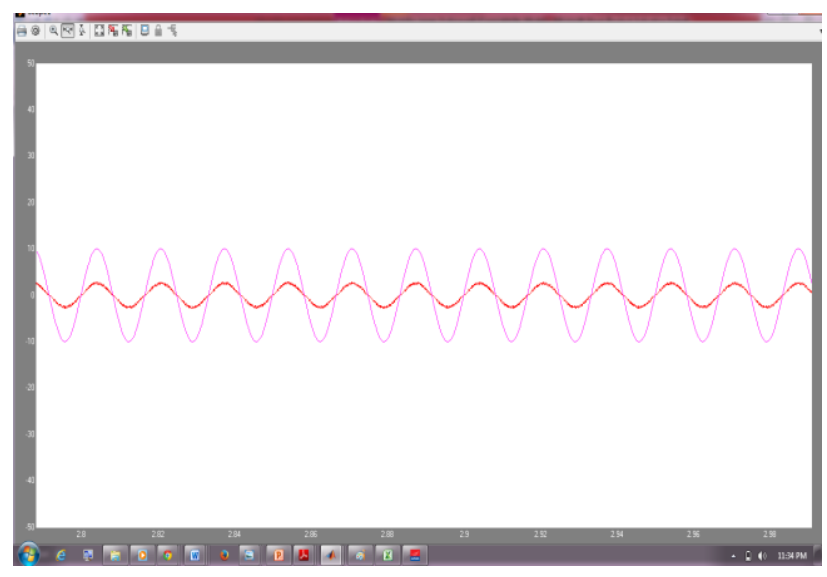

Fig.5 (a): Phase A input Voltage and Current Waveform

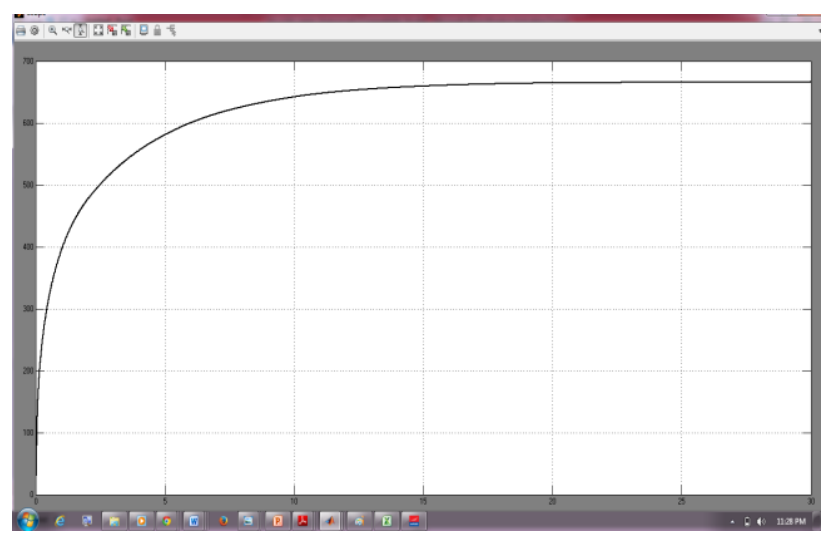

Fig.5 (b): Output DC Voltage at 670V for input $100 \mathrm{VAC}$

\section{CONCLUSIONS}

This paper proposed a three phase, three switches and three levels Vienna rectifier circuit for wind power generation that is varying input voltage is simulated. From the simulation results it is observed that input phase current is in phase with the input phase voltage hence unity power factor and reduced harmonic levels. It is also observed that it is possible to compensate PF and THD for varying input voltage level by using the proper switching control scheme. A new technique of phase locked loop and power factor correction control strategy compensate input imbalances of wind power generation system.

\section{ACKNOWLEDGEMENTS}

The Authors would like to thank DR.B.Rajesh Kamath, Head of the Dept. EEE,SSIT, Tumkur for his constant support and valuable comments in carrying out this work. The Authors would like to thank Prof. K L Ratnakar, Professor, EEE Dept., SSIT, and Tumkur for his guidance and constant supervision in carrying out this work. The authors highly indebted to LnT Integrated Engineering Services, Mysore for hosting the work.

\section{REFERENCES}

[1]. J.W. Kolar and H. Ertl, "Status of the Techniques of Three-Phase Rectifier Systems with Low Effects on the Mains", 21st INTELEC, Copenhagen, Denmark, pp.14.1 June 1999.

[2]. M. Tou, K. Al-Haddad, G. Olivier and V.R. Rajagopalan, "Analysis and Design of Single-Controlled Switch ThreePhase Rectifier with Unity Power Factor and Sinusoidal Input Current", IEEE Transactions on Electronics, Vol. 2, No. 4, pp.856-862, July 1997

[3]. A.D. Pathak, R. E. Locher, H.S.Mazumdar,'3-Phase Power Factor Correction, Using Vienna Rectifier Approach and Modular Construction For Improved Overall Performance, Efficiency and Reliability", Power electronics Conference, CA, USA, 2003.

[4]. G.Radomski, “Analysis of Vienna Rectifier", Technical university of Kielce, Poland, Electrical power quality and utilization, Journal Vol.XI, No.1, 2005.

[5]. H.Chen, D.C. Aliprantis," Induction Generator with Vienna Rectifier: Feasibility Study for Wind Power Generation", .XIX international conference on electric Machines-ICEM, Rome, 2010.

[6]. Rajesh Ghosh and G. Narayanan, "A Single-Phase Boost Rectifier System for Wide Range of Load Variations", IEEE transactions on power electronics, vol. 22, no. 2, march 2007

[7]. Mustafa Mohamadian and Amirhossein Rajaei,'ViennaRectifier-Based Direct Torque Control of PMSG for Wind Energy Application", IEEE transactions on industrial electronics, July 2013

[8]. Mitulkumar R. Dave, K.C.Dave "Analysis of Boost Converter Using PI Control Algorithms", International Journal of Engineering Trends and Technology, July 2012 